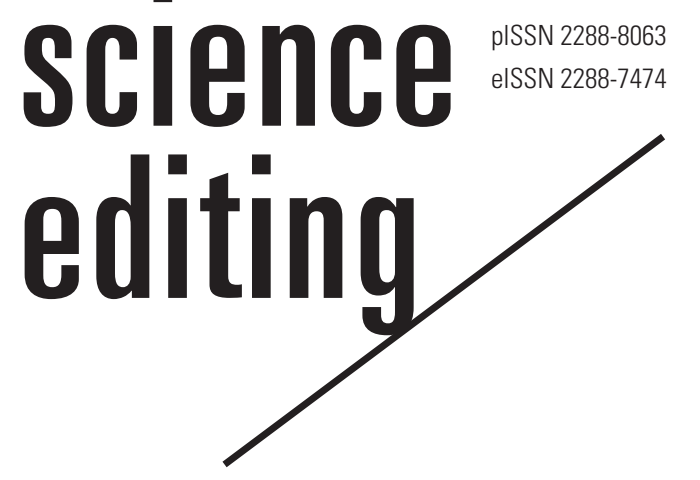

\title{
Publons joins Clarivate Analytics: what would be the future?
}

\section{Essay}

\author{
Aamir Raoof Memon' ${ }^{1}$, Ahmed Waqas ${ }^{2}$ \\ ${ }^{1}$ Institute of Physiotherapy \& Rehabilitation Sciences, Peoples University of Medical \& Health Sciences for Women, \\ Nawabshah; ${ }^{2} \mathrm{CMH}$ Lahore Medical College \& Institute of Dentistry, Lahore Cantt, Pakistan
}

\section{Introduction}

This year showcased a burst of changes starting with the introduction of CiteScore (https:// journalmetrics.scopus.com/), followed by the mysterious shutdown of Beall's blog [1,2]. Scientific publishing is based on the principles of transparency and credibility which aims at improving the quality, visibility and access to research. However, unfortunately, it has evolved from an exploratory model to a business model [3]. In such a situation, scholarly publishing is getting transformed from being a relatively financially conflict-free zone of intellectual achievement into a marketing tool where open access, metrics, and peer review are commercialized [3]. Especially in a non-abating altmetrics trend, where publishing giants and companies are racing for dominance, scientific publishing has to witness further, numerous facts, news and events. One such news came on June 1, 2017, when Publons, a reviewer- and editor-recognition platform, joined Clarivate Analytics, a metrics giant. This essay discusses the possible influence of their amalgamation among scientific publishing.

\section{Peer Review Process and Publons}

Like many other aspects, the peer review process has been considered the cornerstone to improve the scholarly publishing process $[4,5]$. Peer review, by definition, is the process involving the critical analysis (done by experts who are not part of the editorial staff) of manuscripts submitted to the journal (or published as individual chapters or monographs) [6]. The concept of peer review dates back to the 17th century and is accepted by the scientific community as

Received: June 13, 2017 Accepted: July 19, 2017

\section{Correspondence to}

Aamir Raoof Memon

dpt.aamir@gmail.com

ORCID

Aamir Raoof Memon http://orcid.org/0000-0002-3203-418X Ahmed Waqas

http://orcid.org/0000-0002-3772-194X the gold standard $[6,7]$. It is generally a voluntary service provided by researchers and academics to the journals where reviewers play an important role, i.e., guiding the substance and direction of a journal $[4,7]$. However, the peer review process has been criticized for several flaws and drawbacks [3-8]. Nevertheless, most of the researchers believe that the peer review is an important component of scholarly publishing for maintaining the transparency, but it should be improved $[4,7]$. A recent study also evaluated the impact of interventions to improve the peer review process [5]. With a combination of use and misuse of indexes and metrics, have there been any indexes for peer reviewers? One of them is the referee factor, proposed as an in- 


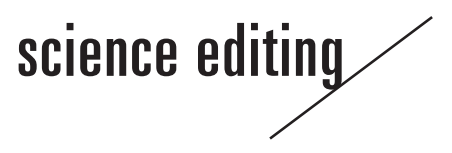

centive for assessments of professional performance, and is defined as the sum of the impact factors for the respective journals multiplied by the number of articles reviewed [6]. But this index has also been subjected to criticism and is not known to many. Alternatively, Publons, which was founded in 2013 , serves as a global peer-review data and recognition platform. It is currently a leading platform for researchers to share, discuss and receive recognition for peer review and editing of academic research with more than 150,000 researchers who are finally getting recognition for more than 800,000 reviews [9]. Moreover, it partners with 26 of the top publishers in the world with more than 1,300 journals included into Publons. Furthermore, the recently launched Publon Academy (https:// publons.com/community/academy/) provides a great training opportunity to researchers and necessary exposure to review researches.

\section{Publons Joins Clarivate Analytics: Possible Implications}

On June 1 2017, Publons joined the Clarivate Analytics, World's largest preeminent citation database investing aggressively to enhance existing analytics. However, prior to this and during the preceding year, the journal impact factor (one of the products of Clarivate Analytics to assess the quality of a journal) faced a heavy-weight rival "CiteScore," resisting its dominating influence on the scholarly community [2]. Might this conjoint between Publons and Clarivate Analytics be a step to keep the influence of Clarivate Analytics alive? It is also noticeable that Clarivate Analytics was recently spun out of Thomson Reuters as a standalone business. Its flagship products like Web of Science, EndNote and ScholarOne, are some of the most widely used tools in research [10]. Moreover, their 'impact factor', one of the research world's first independent measures of journal quality, has dominated the world of scientometrics for over 60 years [2]. What influence might this amalgamation have on scientific publishing? There is a possibility that Publons may expand the project and get powerful due to the funding support backed by the Clarivate Analytics, which may ultimately improve research integrity and recognition of reviewers. Conversely, Publons might become politicized just like the controversial impact factor [2]. Currently, Publons indexes numerous journals, however, it is subjected to inclusion of predatory journals. After joining Clarivate Analytics, this may be assumed that it might improve the quality of inclusion of journals in it. It might also be noticed that just after this event, Publons have modified their user interface.

\section{Conclusion}

The year 2017 has seen many events related to scientific publishing. In the race of increasing scientometrics and research commercialization between publishing giants affecting several other aspects of research, integrity and transparency has to improve. The recent amalgamation of Publons and Clarivate Analytics is the news of the time for 2017. There is a possibility of bilateral outcomes. It is possible that the Publons will either improve its standards after this event and will facilitate science or it will be politicized just like the controversial impact factor; either transparency will improve or monopoly will prevail, only time will reveal the results.

\section{Conflict of Interest}

No potential conflict of interest relevant to this article was reported.

\section{References}

1. Memon AR. Beall's list has vanished: what next? J Orthop Sports Phys Ther 2017;47:219-23. https://doi.org/10.2519/ jospt.2017.0202

2. Teixeira da Silva JA, Memon AR. CiteScore: a cite for sore eyes, or a valuable, transparent metric? Scientometrics 2017; 111:553-6. https://doi.org/10.1007/s11192-017-2250-0

3. Teixeira da Silva JA. Fake peer reviews, fake identities, fake accounts, fake data: beware! AME Med J 2017;2:28. https: //doi.org/10.21037/amj.2017.02.10

4. Swartz MK. The importance of peer review. J Pediatr Health Care 2008;22:333-4. https://doi.org/10.1016/j.pedhc. 2008.08.004

5. Bruce R, Chauvin A, Trinquart L, Ravaud P, Boutron I. Impact of interventions to improve the quality of peer review of biomedical journals: a systematic review and meta-analysis. BMC Med 2015;14: 85. https://doi.org/10.1186/s12916016-0631-5

6. Cintas P. Peer review: from recognition to improved practices. FEMS Microbiol Lett 2016;363:fnw115. https://doi. org/10.1093/femsle/fnw115

7. Manchikanti L, Kaye AD, Boswell MV, Hirsch JA. Medical journal peer review: process and bias. Pain Physician 2015; 18:E1-14.

8. Kim K. Can we improve the peer review system? Sci Ed 2017;4:1-2. https://doi.org/10.6087/kcse.81

9. Preston A. Publons joins Clarivate Analytics: the future of peer review [Internet]. Publons; 2017 [cited 2017 Jun 1]. Available from: https://publons.com/blog/publons-joinsclarivate-analytics/?utm_source=PublonsUsers\&utm 
campaign $=9 \mathrm{a} 0 \mathrm{~b} 7 \mathrm{dfc} 4 \mathrm{c}$-Clarivate_announcement\&utm medium $=$ email\&utm_term $=0 \_d 203 e c 3 f 11-9 \mathrm{a} 0 \mathrm{~b} 7 \mathrm{df}-$ c4c-136208157

10. PR Newswire. Clarivate Analytics acquires market leader Publons, creating the definitive publisher-independent platform for accelerating research through peer review
[Internet]. PR Newswire; 2017 [cited 2017 Jun 1]. Available from: http://www.prnewswire.com/news-releases/ clarivate-analytics-acquires-market-leader-publons-creating-the-definitive-publisher-independent-platform-foraccelerating-research-through-peer-review-300466622. html 